\title{
Methods of modelling relative growth rate
}

\author{
Arne Pommerening ${ }^{*}$ and Anders Muszta
}

\begin{abstract}
Background: Analysing and modelling plant growth is an important interdisciplinary field of plant science. The use of relative growth rates, involving the analysis of plant growth relative to plant size, has more or less independently emerged in different research groups and at different times and has provided powerful tools for assessing the growth performance and growth efficiency of plants and plant populations. In this paper, we explore how these isolated methods can be combined to form a consistent methodology for modelling relative growth rates.

Methods: We review and combine existing methods of analysing and modelling relative growth rates and apply a combination of methods to Sitka spruce (Picea sitchensis (Bong.) Carr.) stem-analysis data from North Wales (UK) and British Douglas fir (Pseudotsuga menziesii (Mirb.) Franco) yield table data.

Results: The results indicate that, by combining the approaches of different plant-growth analysis laboratories and using them simultaneously, we can advance and standardise the concept of relative plant growth. Particularly the growth multiplier plays an important role in modelling relative growth rates. Another useful technique has been the recent introduction of size-standardised relative growth rates.

Conclusions: Modelling relative growth rates mainly serves two purposes, 1) an improved analysis of growth performance and efficiency and 2) the prediction of future or past growth rates. This makes the concept of relative growth ideally suited to growth reconstruction as required in dendrochronology, climate change and forest decline research and for interdisciplinary research projects beyond the realm of plant science.
\end{abstract}

Keywords: Growth efficiency; Growth coefficient/multiplier; Chapman-Richards growth model; Standardisation; Simultaneous estimations

\section{Background}

Growth is a universal and fundamental process of life on earth. The analysis and modelling of plant growth has therefore been a particular concern in plant science as well as in production biology including forestry, agriculture and fishery to name but a few. This research has the important objective to identify growth patterns in response to environmental factors or treatments.

In this context, the concept of relative plant growth, involving the analysis and modelling of plant growth relative to plant size, has proved to be a powerful tool in comparative studies of the growth performance of plants and has a long tradition in plant science (Evans 1972, p. 190ff.; Pommerening and Muszta: Concepts of relative growth - a review, submitted). It first developed at the beginning of the $20^{\text {th }}$ century in what eventually became

\footnotetext{
* Correspondence: arne.pommerening@slu.se

Department of Forest Resource Management, Faculty of Forest Sciences,

Swedish University of Agricultural Sciences SLU, Skogsmarksgränd, SE-901 83
} Umeå, Sweden the British school of plant growth analysis, mainly at Sheffield University (Hunt 1982, p. 1, 16).

Independently of the British school another quantitative plant science group developed at Tharandt/Dresden Technical University in Germany. The Tharandt school characterised the growth of trees by using a variant of the concept of relative plant growth and on this basis eventually developed a population model and a size class model for predicting the growth of trees (Wenk et al. 1990, Wenk 1994). There is also evidence of empirical Russian work in this area (Antanaitis and Zagreev 1969) and particularly remarkable is the detailed Finnish work by Kangas (1968).

Relative growth rate is a standardised measure of growth with the benefit of avoiding, as far as possible, the inherent differences in scale between contrasting organisms so that their performances can be compared on an equitable basis (Hunt 1990, p. 6). Applications of relative growth rates include the study of dry weight, biomass, leaf area, stem volume, basal area and stem

\section{Springer}


diameter. Interestingly, the concept is closely related to plant mortality (Gillner et al. 2013), i.e. low relative growth rates for extended periods of time are good indicators of imminent death. Relative growth rates are also pre-requisites for quantifying and modelling allometric relationships in plants (Gayon 2000).

Assuming that function $y(t)$ models the state of a plant characteristic at time $t$, for example the weight, area, volume or biomass of a plant, relative growth velocity or instantaneous relative growth rate (RGR; in forestry termed relative increment) can be expressed as

$$
p(t)=\frac{\mathrm{d}}{\mathrm{d} t} \log y(t)=\frac{\mathrm{d} y}{\mathrm{~d} t} \times \frac{1}{y(t)}=\frac{y^{\prime}(t)}{y(t)}
$$

As instantaneous growth rates cannot be measured in practice, the difference between growth characteristics of interest is usually studied at discrete points in time, $t_{1}$, $t_{2}, \ldots, t_{n}$, which for example are scheduled survey years. In this context, the period between two discrete points in time can be denoted by $\Delta t=t_{k}-t_{k-1}$ with $k=2, \ldots, n$. For ease of notation in the remainder of this section we set $y\left(t_{k}\right)=y_{k}$ and $p\left(t_{k}\right)=p_{k}$ etc. and assume equidistant time periods. However, the notation can be modified to accommodate unequal time periods (Pommerening and Muszta: Concepts of relative growth - a review, submitted).

According to Blackman (1919), Whitehead and Myerscough (1962) and Hunt (1982, 1990), periodic relative increment or mean relative growth rate, $p_{k}$, over a time period $\Delta t$ is the difference of the logarithms of $y_{k}$ and $y_{k-1}$ divided by $\Delta t$, see also Causton (1977, p. 213).

$$
\begin{aligned}
p_{k} & =\frac{\log y_{k}-\log y_{k-1}}{t_{k}-t_{k-1}}=\frac{\log y_{k}-\log y_{k-1}}{\Delta t} \\
& =\frac{\log \left(y_{k} / y_{k-1}\right)}{\Delta t}
\end{aligned}
$$

Considering a short time period, mean relative growth rate is approximately equal to the instantaneous relative growth rate $p(t)$. Blackman (1919) originally referred to equation (2) as "efficiency index" and "specific growth rate", see also Causton and Venus (1981, p. 37). From the last term we can see that equation (2) can be interpreted as the logarithm of the ratio of successive size measurements divided by the corresponding time interval (Pommerening and Muszta: Concepts of relative growth - a review, submitted).

According to Evans (1972, p. 197) and Hunt (1982, p. 17), the current value of a plant characteristic can be calculated from a value in the past based on equation (2) as

$$
y_{k}=y_{k-1} \cdot e^{p_{k} \cdot \Delta t}
$$

Equation (3) is also referred to as Blackman's efficiency index which is supposed "to represent the efficiency of the plant as a producer of new material, and to give a measure of the plant's economy in working" (Blackman 1919).

The exponential term in equation (3) has fascinated plant growth scientists and inspired them to devise special names. Kangas (1968, p. 50f.) coined the name growth coefficient, whereas Wenk (1972) suggested the name growth multiplier, $M_{k}$ (equation 4).

$$
M_{k}=e^{P_{k} \cdot \Delta t}=\frac{y_{k}}{y_{k-1}}
$$

The growth coefficient or multiplier is obviously a function of relative growth rate and can also be defined as the ratio of a particular plant size characteristic at different times. Part of the fascination with $M_{k}$ stems from the fact that the growth multiplier plays a crucial role in predicting future growth based on relative growth rates (Kangas 1968, p. 19; Wenk et al. 1990, p. 95f.; Murphy and Pommerening 2010).

The allometric coefficient, $m_{k}$, mediates relative changes of plant size characteristics, e.g. $x$ and $y$ (where $y$ has the same meaning as in the equations before). $m_{k}$ is an important part of the concept of relative growth (Gayon 2000). Considering short time periods it is often assumed that the allometric coefficient is constant. Wenk (1978) could show that in such a case the mean relative growth rates $p_{x}$ and $p_{y}$ of size characteristics $x$ and $y$ are related as

$$
p_{x, k}=1-\left(1-p_{y, k}\right)^{\frac{1}{m_{k}}}
$$

The objective of this paper is to explore how relative growth rates of individual plants as well as of plant populations can be efficiently analysed and modelled using a system of simultaneous functions of relative growth and allometric relationships developed in different research schools.

\section{Functions of relative growth}

Hunt (1982), Wenk et al. (1990, p. 79) and Zeide (1993) give a number of plant growth functions and provide detailed discussions. They are often combinations of power functions and exponential functions (Zeide 1989). Zeide (1993) and Pommerening and Muszta (Concepts of relative growth - a review, submitted) show how they relate to each other. These authors also compiled a number of functions of relative growth, which are reproduced in Table 1.

The functions in Table 1 are based on the original growth functions and on the corresponding functions of absolute growth rate, i.e. the first derivatives of the 
Table 1 Frequently used functions of absolute and relative plant growth rate. $a, b, c$ are model parameters and the symbol $t$ denotes time or age

\begin{tabular}{llll}
\hline Function name/source & Growth function & Absolute growth rate & Relative growth rate \\
\hline Chapman-Richards (Richards 1959) & $a\left(1-e^{-b t}\right)^{c}$ & $a b c e^{-b t}\left(1-e^{-b t}\right)^{c-1}$ & $b c\left(1-e^{-b t}\right)^{-1}$ \\
Gompertz (1825) & $a e^{-b e^{-c t}}$ & $a b c e^{-c t} e^{-b e^{-c t}}$ & $b c e^{-c t}$ \\
Kangas (1968) & - & - & $a e^{b t^{-c}}$ \\
Korf (Zeide 1993) & $a e^{-b t^{-c}}$ & $a b c t^{-c-1} e^{-b t^{-c}}$ & $b c t^{-(1+c)}$ \\
Logistic (Verhulst 1838) & $a\left(1+c e^{-b t}\right)^{-1}$ & $a b c e^{-b t}\left(1+c e^{-b t}\right)^{-2}$ & $b c\left(c+e^{b t}\right)^{-1}$ \\
Monomolecular (Weber 1891) & $a\left(1-c e^{-b t}\right)$ & $a b c e^{-b t}$ & $b c\left(e^{b t}-c\right)^{-1}$ \\
Weibull (Zeide 1993) & $a\left(1-e^{-b t^{c}}\right)$ & $a b c t^{c-1} e^{-b t^{c}}$ & $b c t^{(c-1)}\left(e^{b t^{c}}-1\right)^{-1}$ \\
\hline
\end{tabular}

growth functions with respect to time. Most functions of relative growth rate have the advantage that they have fewer model parameters than the corresponding functions of absolute growth rate.

Kangas (1968, p. 69) independently suggested the function listed in Table 1 next to his name for modelling the growth multiplier of equation (4) and referred to it as the growth coefficient function.

\section{Modelling individual plant growth}

The strategy of modelling individual plant growth is straightforward: 1) A suitable function of relative growth rate is selected from Table 1 or from other publications. 2) A primary plant size characteristic is identified, e.g. tree volume. 3) Secondary plant size characteristics, e.g. tree height and tree diameter, are linked to the function of relative growth rate of the primary plant size characteristic through allometric relations. 4) The 2-3 model parameters of the function of relative growth rate and the two allometric coefficients are estimated simultaneously through nonlinear regression. Jones et al. (2009, p. 219f.) describe how such more complex types of nonlinear regression can be calculated in $\mathrm{R}$ using the function optim.

Wenk et al. (1990, p. 174ff.) selected primary and secondary plant size characteristics in such a way that error propagation was effectively reduced: They identified tree volume as a three-dimensional size characteristic to be the primary characteristic and one-dimensional total tree height and stem diameter as secondary characteristics. However, since this is a generic approach, there is no need to strictly follow this recommendation. Tree volume can for example also be replaced by weight or biomass.

To illustrate this combined methodology we have used stem-analyses data of four Sitka spruce (Picea sitchensis (Bong.) Carr.) trees taken from the same forest stand in Clocaenog Forest (North Wales, UK). Stem-analysis data include annual tree size characteristics such as stem volume, total tree height and stem diameter at $1.3 \mathrm{~m}$ above ground level. As function of relative growth we selected the well-known and frequently used Chapman-Richards function, but any of the other functions in Table 1 would perform reasonably similar (Pommerening and Muszta: Concepts of relative growth - a review, submitted). As an example, Figures 1 and 2 give a visual impression of

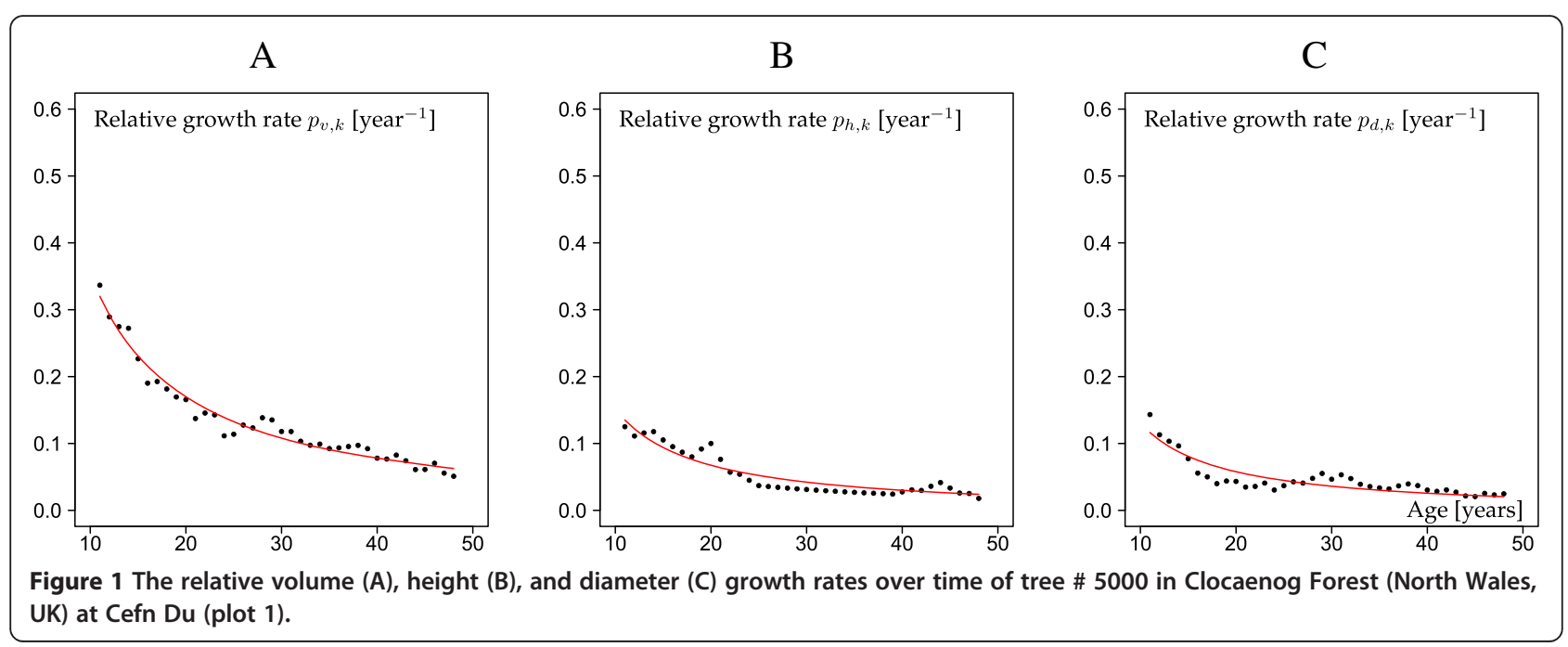




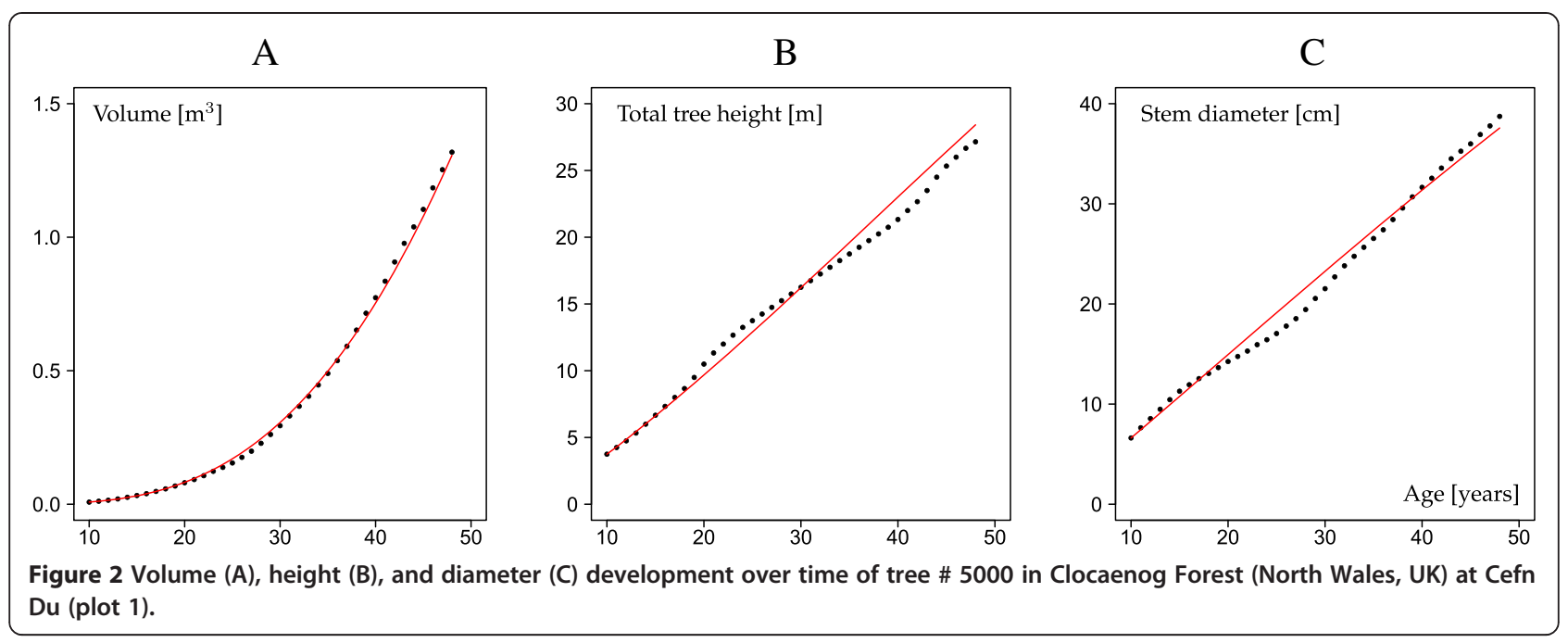

the regression results of tree \# 5000. The corresponding model parameters and other summary statistics can be found in Table 2.

The relative growth curve of volume, $p_{v, k}$, in Figure 1 (A) is based on the Chapman-Richards model (see Table 1) with model parameters $b$ and $c$. The relative height (Figure 1, B) and diameter (Figure 1, C) growth rates, $p_{h, k}$ and $p_{d, k}$, however, have not been modelled independently but linked to $p_{v, k}$ through the allometric coefficients $m_{1}$ and $m_{2}$ and equation (5).

Figure 2 demonstrates how the relative growth rates of tree \# 5000 "translate" to modelling the observed growth characteristics using the growth multiplier of equation (4). Again, any other growth characteristics can be used instead of volume, total height and stem diameter, the growth analyst is completely free to choose.

Figure 3 (A) summarises the curves of relative volume growth rate curves of all four trees.

As expected the three curves decline throughout growth and particularly trees \# 2000, 3000 and 4000 appear to have quite similar growth patterns, as is often the case with trees of the same population growing in similar environmental conditions. Their curves form almost parallel lines in the order $4000>3000>2000$, i.e. tree \# 4000 has the highest relative growth rate throughout its lifetime and tree \# 2000 the lowest. This trend also seems to be reflected by model parameter $b$, which is responsible for scaling the growth rate (Pienaar and Turnbull 1973), although this requires a more detailed study.

Tree \# 5000 exhibits a growth pattern different from the other three trees: Its growth starts with a comparatively low rate, but finishes with a rate markedly higher than those of the other three trees. The curve of Tree \# 5000 intersects those of the others approximately halfway through its lifetime.

The data of all four trees start at the same age (10 years) and end approximately at the same age (48-50 years). Trees \# 2000 and 5000 are larger than the other two trees at the beginning, whilst trees \# 5000 and 4000 are the largest at the end of their lifetime.

Many authors point out that RGR is size dependent, i.e. individuals with a smaller initial size have a larger relative growth rate (Turnbull et al. 2008; Rose et al. 2009; Rees et al. 2010). This can mask important relationships and it may be difficult to tell whether a tree grows slowly because it is large or because it is pursuing a slow growth strategy. To check up on this argument

Table 2 Characteristics and model statistics of four Sitka spruce (Picea sitchensis (Bong.) Carr.) trees at Cefn Du (plot 1), Clocaenog Forest (North Wales, UK)

\begin{tabular}{|c|c|c|c|c|c|c|c|c|c|c|}
\hline \multirow{2}{*}{$\begin{array}{l}\text { Tree } \\
\#\end{array}$} & \multicolumn{2}{|c|}{$d b h(\mathrm{~cm})$} & \multirow[t]{2}{*}{$b$} & \multirow[t]{2}{*}{ c } & \multicolumn{2}{|c|}{ Volume $\left(\mathrm{m}^{3}\right)$} & \multicolumn{2}{|c|}{ Total height $(\mathrm{m})$} & \multicolumn{2}{|c|}{ Stem diameter $(d b h)$} \\
\hline & Min. & Max. & & & Bias & RMSE & $m_{1}$ & RMSE & $m_{2}$ & RMSE \\
\hline 2000 & 6.4 & 32.2 & -0.05251 & 6.12877 & 0.00303 & 0.02478 & 2.82205 & 0.01309 & 1.07431 & 0.02211 \\
\hline 3000 & 4.2 & 28.3 & -0.05057 & 6.44977 & 0.00307 & 0.01646 & 2.63452 & 0.00633 & 1.04791 & 0.01835 \\
\hline 4000 & 4.9 & 32.6 & -0.04667 & 6.40575 & 0.00249 & 0.02401 & 2.78971 & 0.01296 & 1.13672 & 0.01294 \\
\hline 5000 & 6.6 & 38.7 & -0.00822 & 3.68512 & 0.00024 & 0.01248 & 2.66006 & 0.01105 & 1.17268 & 0.01218 \\
\hline
\end{tabular}

$d b h$ - stem diameter at breast height at $1.3 \mathrm{~m}$ above ground level; $b, c$ - model parameter of the Chapman-Richards model of relative growth rate; $m_{1}, m_{2}-$ allometric coefficients for estimating the relative growth rates of total height and stem diameter, respectively. Bias and RMSE relate to estimates of relative growth rates. 

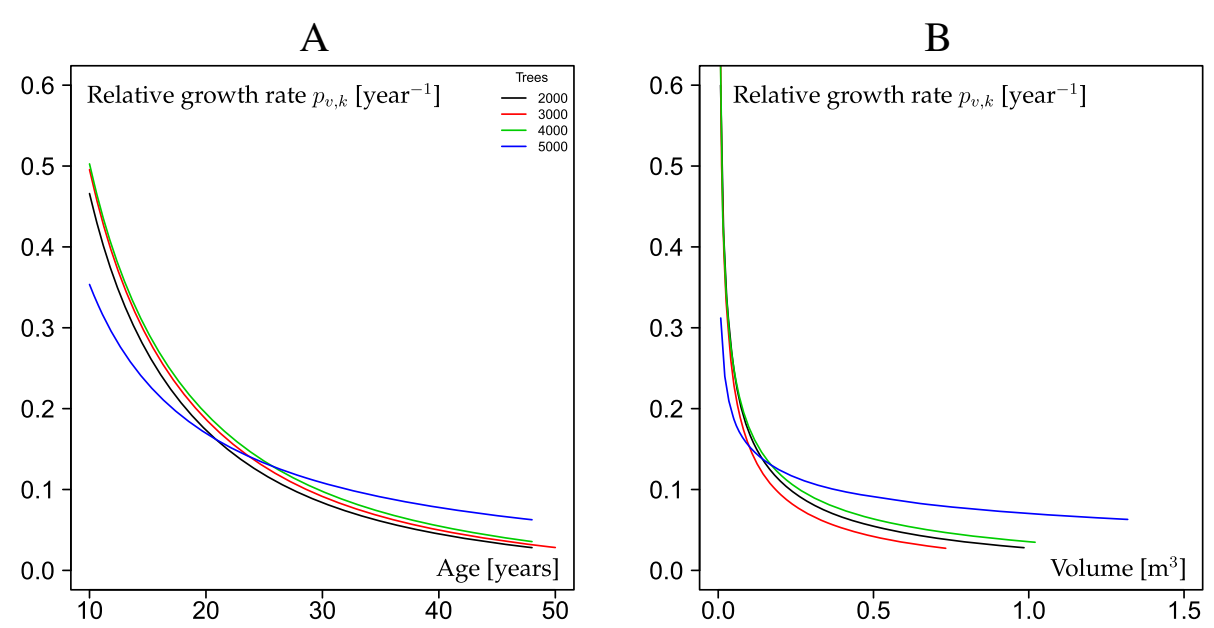

Figure 3 Relative volume growth rates of four trees at Cefn Du (plot 1), Clocaenog Forest (North Wales, UK). A: Relative volume growth rates over time modelled using the Chapman-Richards growth function. B: The standardised relative volume growth rates over volume of the same trees based on the same growth model as before.

we can calculate size-standardised RGR. To this end, first the Chapman-Richards growth function (see first row in Table 1) is fitted to the observed size data of the four trees.

Inverting the Chapman-Richards growth curve provides a possibility to convert volume (or any other size characteristic) to time/age, see equation (6) (which obviously is different for other growth functions in Table 1).

$$
t=-\frac{\ln \left(1-e^{\left.\ln \frac{(y)}{a}\right)}\right)}{b}=-\frac{1}{b} \cdot \ln \left(1-\left(\frac{y}{a}\right)^{\frac{1}{c}}\right)
$$

This conversion of time to a growth characteristic on the abscissa allows depicting size-standardised RGR in Figure 3 (B). We get a better understanding of the differences in relative volume growth rate of the four trees and see more clearly that tree \# 5000 due to the lower rate of decline has a superior relative growth rate throughout most of its volume development despite the fact that its initial RGR is much lower than those of the other trees. Also the ordering of trees \# 2000 and 3000 is interestingly reversed compared to non-standardised RGR (Figure 3, A). We can also see that tree \# 3000 is the tree with the smallest final volume despite having a longer lifespan than all other trees.

As RGRs and growth multipliers are measures of relative growth it seems natural to relate them to relative size variables. The stem diameter growth multiplier of individual trees of the next time step, $M_{d, k+1}$, is for example correlated with their current stem diameters, $d b h_{k}$, relative to the current quadratic population diameter, $d g_{k}$, i.e. $d_{\text {rel, } k}=d b h_{k} / d g_{k}$. Figure 4 illustrates this relationship for the conifer trees of a mixed conifer- broadleaved woodland at Coed y Brenin (plot 7, North Wales, UK). As a model function to describe this relationship the Michaelis-Menten saturation curve (Michaelis and Menten 1913; Bolker 2008) was used, as it appears to describe the data well.

Apparently the diameter multiplier decreases with increasing tree size relative to the population mean and levels off with very large ratios when trees are much larger than the population mean. Using the relationship between a relative tree diameter and the growth multiplier

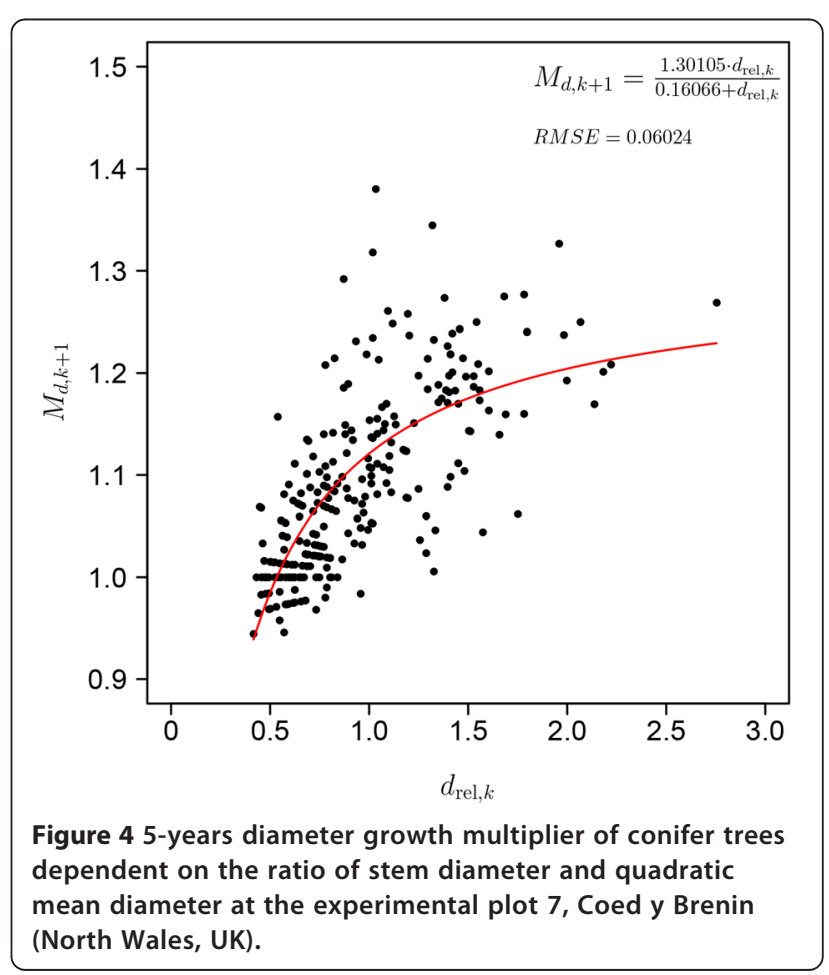


also has the advantage of predicting future growth from current size and from size dominance at the same time. Coming back to the relationship between relative growth rate and mortality (Gillner et al. 2013), trees in the lower range of $M_{d, k+1}$ carry a high probability of dying.

\section{Modelling of plant populations}

In the same way as it is possible to model individual plants one can also model whole plant populations. In this case, the growth rates are calculated from population summary characteristics. Details of this approach are also documented in Wenk and Nicke (1985), Nicke (1988) and in Wenk (1994).

Drawing an analogy to the example used in the previous section we can for example model volume per hectare, top height and quadratic mean diameter of a forest stand. Let us denote the corresponding relative growth rates as $p_{V, k}, p_{H, k}$, and $p_{D, k}$ using capital letters for population volume $(V)$, height $(H)$ and diameters $(D)$ in the subscripts. The methodology is almost exactly the same with the exception that there is a need to account for trees leaving the forest stand. These losses can be due to forest management or to natural mortality or can be a combination of both. For simplicity we introduce just one additional function that we simply refer to as loss function here, $l_{V, k}$, to collectively take care of death events as a result of disturbances. This function was suggested by Wenk et al. (1990, p. 159).

$$
l_{V, k}=1-\frac{Q}{M_{V, k}},
$$

where $Q$ is the ratio $V_{k+1}^{\text {res }} / V_{k}^{\text {res }}$, i.e. the ratio of successive residual stand volumes (superscript "res" denotes "residual"). The ratio $Q$ defines the loss and must not exceed the volume growth multiplier, as negative values are not defined. With $Q=1, p_{V, k}=l_{V, k}$ and the forest stand does not grow. The loss function is therefore a ratio of two multipliers subtracted from one and can also be estimated with the Chapman-Richards relative growth rate function.

Forest stand volume is then calculated and projected in the following way (considering that the superscripts "prior" define the forest state before disturbance, "lost" the part of the tree population lost and "res" the state of the residual forest after disturbance):

$$
\begin{aligned}
V_{k}^{\text {lost }} & =V_{k}^{\text {prior }} \cdot l_{v, k} \\
V_{k}^{\text {res }} & =V_{k}^{\text {prior }}-V_{k}^{\text {lost }} \\
V_{k+1}^{\text {prior }} & =V_{k}^{\text {res }} \cdot M_{V, k+1}
\end{aligned}
$$

In a first step, the volume per hectare of dead trees, i.e. the absolute loss in terms of volume, is calculated as the product of the volume of the forest stand before the disturbance, $V_{k}^{\text {prior }}$, and the volume loss rate, $l_{V, k}$. Then residual stand volume, $V_{k}^{\text {res }}$, constitutes the difference between stand volume before disturbance, $V_{k}^{\text {prior }}$, and the absolute volume loss, $V_{k}^{\text {lost }}$. Finally the volume of the forest stand before disturbance for the next time step, $V_{k+1}^{\text {prior }}$, is calculated as the product of the residual stand volume of the current time step, $V_{k}^{\text {res }}$, and the volume growth multiplier of the next time step, $M_{V, k+1}$.

In analogy to volume projection, the development of a density measure such as trees per hectare can be modelled. Stand height is also modelled in a similar way as outlined in the last line of equation (9) and like individual-tree heights.

Finally, the quadratic mean diameter, $d g_{k}^{\text {prior }}$, of the forest stand before disturbance is calculated from stand basal area before disturbance, $G_{k}^{\text {prior }}$, and the number of trees per hectare before disturbance, $N_{k}^{\text {prior }}$, using the following two equations.

$$
\begin{aligned}
G_{k}^{\text {prior }} & =\frac{V_{k}^{\text {prior }}}{f_{H}} \\
d g_{k}^{\text {prior }} & =100 \cdot \sqrt{\frac{4 \cdot G_{k}^{\text {prior }}}{\pi \cdot N_{k}^{\text {prior }}}}
\end{aligned}
$$

$f_{H}$ is a static form height function. Such form height relationships are available for many species and countries.

The equations of this section can be included in a regression routine, for example in the optim function of $\mathrm{R}$ mentioned before (Jones et al. 2009, p. 219f.). As a function of relative growth rate we again select the Chapman-Richards function (see Table 1), but any of the other functions is suitable, too.

To illustrate this method we have used Douglas fir (Pseudotsuga menziesii (Mirb.) Franco) data from British yield tables (Edwards and Christie 1981), specifically those relating to yield class 24 , initial spacing $1.7 \mathrm{~m} \times 1.7 \mathrm{~m}$ and crown thinning. Yield tables can be interpreted as tabular summary characteristics of forest stands, whereby the yield classes represent different environmental conditions resulting in a larger or smaller carrying capacity. Naturally any other aggregated plant population data can be selected for this purpose.

The yield table data are provided for five-year intervals and as a consequence relative growth rates and growth multipliers also relate to 5 -years periods.

In addition to the yield table data, we have used the UK form height function for Douglas fir suggested by Matthews and Mackie (2006, p. 325):

$$
f_{H}=-0.509255+0.426679 \cdot H,
$$

where $H$ is stand top height in metres.

Figure 5 (A) shows the relative volume growth rate at forest stand level, $p_{V, k}$, and the relative volume loss rate, 
A

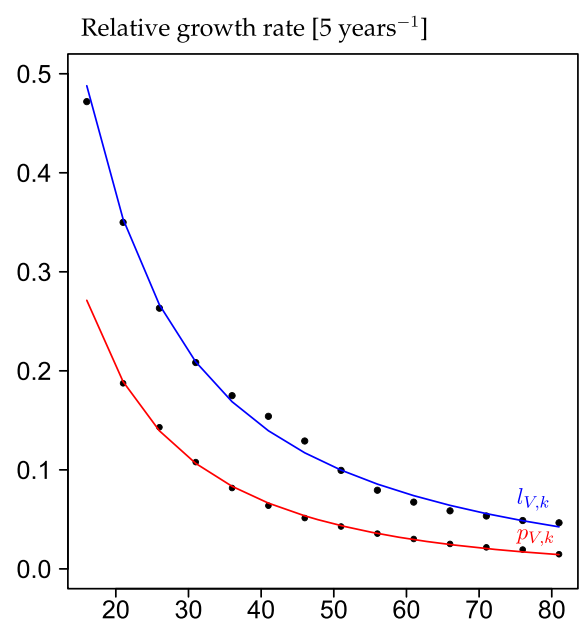

B

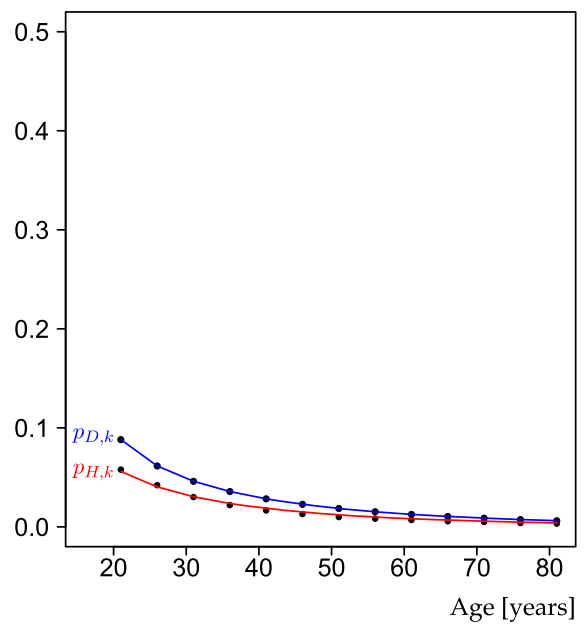

Figure 5 Relative growth rates of the British Douglas fir (Pseudotsuga menziesii (Mirb.) Franco) yield class model for yield class 24, initial spacing $1.7 \mathrm{~m} \times 1.7 \mathrm{~m}$ and crown thinning (Edwards and Christie 1981). A: The relative volume growth rate (red) and relative loss rate (blue) $\mathbf{B}$ : The corresponding relative growth rates of the quadratic mean stem diameter height (blue) and of top height (red).

$l_{V, k}$. Note that $p_{V, k}<l_{V, k}$ at all times to fulfil the aforementioned requirement that $Q$ must not exceed the volume growth multiplier.

Figure 5 (B) gives the quadratic mean stem diameter and top height relative growth rates over time. They start at a much lower rate than the relative volume growth rate and are related to it by the allometric coefficient $m$. Table 3 gives data and model summary characteristics.

Figure 6 presents the temporal development of the actual population size characteristics volume per hectare, top height and quadratic mean diameter. Again they have been calculated from relative growth rates as explained in equation systems (8) and (9).

We can now take a look at the relative volume growth rates of the four Douglas fir yield classes 8, 12, 18 and 24 (Figure 7, A). Interestingly the relative growth rates almost do not differ at all, only the curve representing yield class 8 is slightly higher than those of the other three. This result is somewhat counter-intuitive assuming that a yield class of 8 represents the least favourable of all four environmental conditions. The outcome suggests that a forest growing on a worse site is relatively more efficiently growing than a forest benefitting from better site factors.

Using again the Chapman-Richards growth function and equation (6) we can calculate standardised relative growth rates resulting in Figure 7 (B).

We can now clearly see that larger yield class numbers, i.e. more favourable environmental conditions, correspond to higher standardised relative growth rates. The standardisation has again helped us to better discriminate between the differences in relative growth rate of the four populations.

\section{Final discussion and conclusions}

Our examples in this paper have demonstrated that by bringing together the approaches in general plant growth analysis and in forest growth and yield science it is possible to advance the concept of relative growth. Modelling of relative growth rates is straightforward and

Table 3 Characteristics and model statistics of four British Douglas fir (Pseudotsuga menziesii (Mirb.) Franco) yield tables (Edwards and Christie 1981) relating to initial spacing $1.7 \mathrm{~m} \times 1.7 \mathrm{~m}$ and crown thinning

\begin{tabular}{|c|c|c|c|c|c|c|c|c|c|}
\hline \multirow{2}{*}{$\begin{array}{l}\text { Yield } \\
\text { class }\end{array}$} & \multicolumn{2}{|c|}{$d g(\mathrm{~cm})$} & \multirow[t]{2}{*}{$b$} & \multirow[t]{2}{*}{$c$} & \multicolumn{2}{|c|}{ Volume $\left(\mathrm{m}^{3} \cdot \mathrm{ha}^{-1}\right)$} & \multicolumn{2}{|c|}{ Top height (m) } & \multirow{2}{*}{$\begin{array}{l}\text { Mean diameter }(d \mathrm{~g}) \\
\text { RMSE }\end{array}$} \\
\hline & Min. & Max. & & & Bias & RMSE & $\bar{m}$ & RMSE & \\
\hline 24 & 12.8 & 76.7 & -0.03240 & 5.68749 & 0.00011 & 0.00185 & 3.64234 & 0.00153 & 0.00658 \\
\hline 18 & 12.2 & 60.9 & -0.03147 & 5.65227 & 0.00014 & 0.00181 & 3.46283 & 0.00151 & 0.00560 \\
\hline 12 & 12.4 & 43.5 & -0.02988 & 5.43637 & 0.00004 & 0.00075 & 3.20122 & 0.00124 & 0.00793 \\
\hline 8 & 11.7 & 32.5 & -0.03095 & 6.16601 & -0.00003 & 0.00072 & 3.06830 & 0.00092 & 0.00757 \\
\hline
\end{tabular}

$d g$ - quadratic mean stem; $b, c$ - model parameter of the Chapman-Richards model of relative growth rate; $m$ - allometric coefficient for estimating the relative growth rate of top height. Bias and RMSE relate to relative growth rates. 

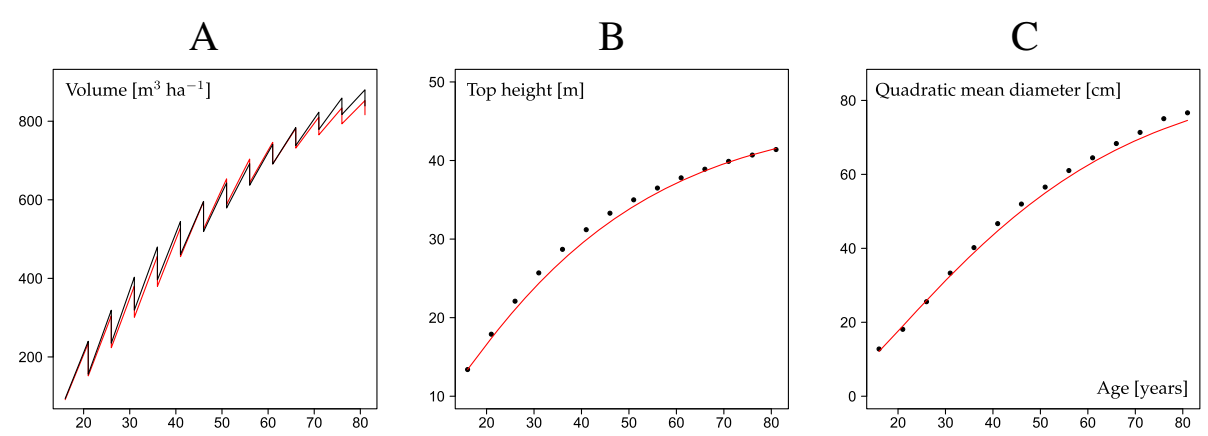

Figure 6 Stand volume (A), top height (B), and quadratic mean stem diameter (C) development over time of the British Douglas fir (Pseudotsuga menziesii (Mirb.) Franco) yield class model for yield class 24, initial spacing $1.7 \mathrm{~m} \times 1.7 \mathrm{~m}$ and crown thinning (Edwards and Christie 1981).

often the corresponding growth functions have fewer model parameters than the respective versions of absolute growth rates. The recent introduction of size-standardised relative growth rates (Turnbull et al. 2008; Rose et al. 2009; Rees et al. 2010) has proved to be very effective for improving our understanding of growth efficiency and this approach can definitely be recommended.

Modelling relative growth rates serves two purposes, 1) an improved analysis of growth performance and efficiency and 2) the prediction of future or past growth rates. The methodology described in this paper also allows "backcasting" by simply dividing plant growth characteristics by the growth multiplier instead of multiplying (Murphy and Pommerening 2010).

The obvious similarity between individual-tree and population modelling of relative growth rates suggests a link between these two modelling levels (see for example
Cao 2014). In short, the idea of this approach is to combine the advantages of different modelling resolutions, particularly to employ information of population models (that are mathematically more tractable and statistically more stable) for improving individual-tree models. This strategy is often referred to as disaggregation. Zhang et al. (1993) describe a method of disaggregation using relative tree sizes similar to $d_{\mathrm{rel}, k}$ shown in this paper. Since this relative size characteristic has also proved useful for modelling growth multipliers, a disaggregation modelling approach for linking the two modelling levels described in this paper is very likely to be successful.

The properties of the concept of relative growth make it a superb choice for growth reconstruction as required in dendrochronology, climate change and forest decline research and we hope that the methodology outlined in this paper will inspire much interdisciplinary research,

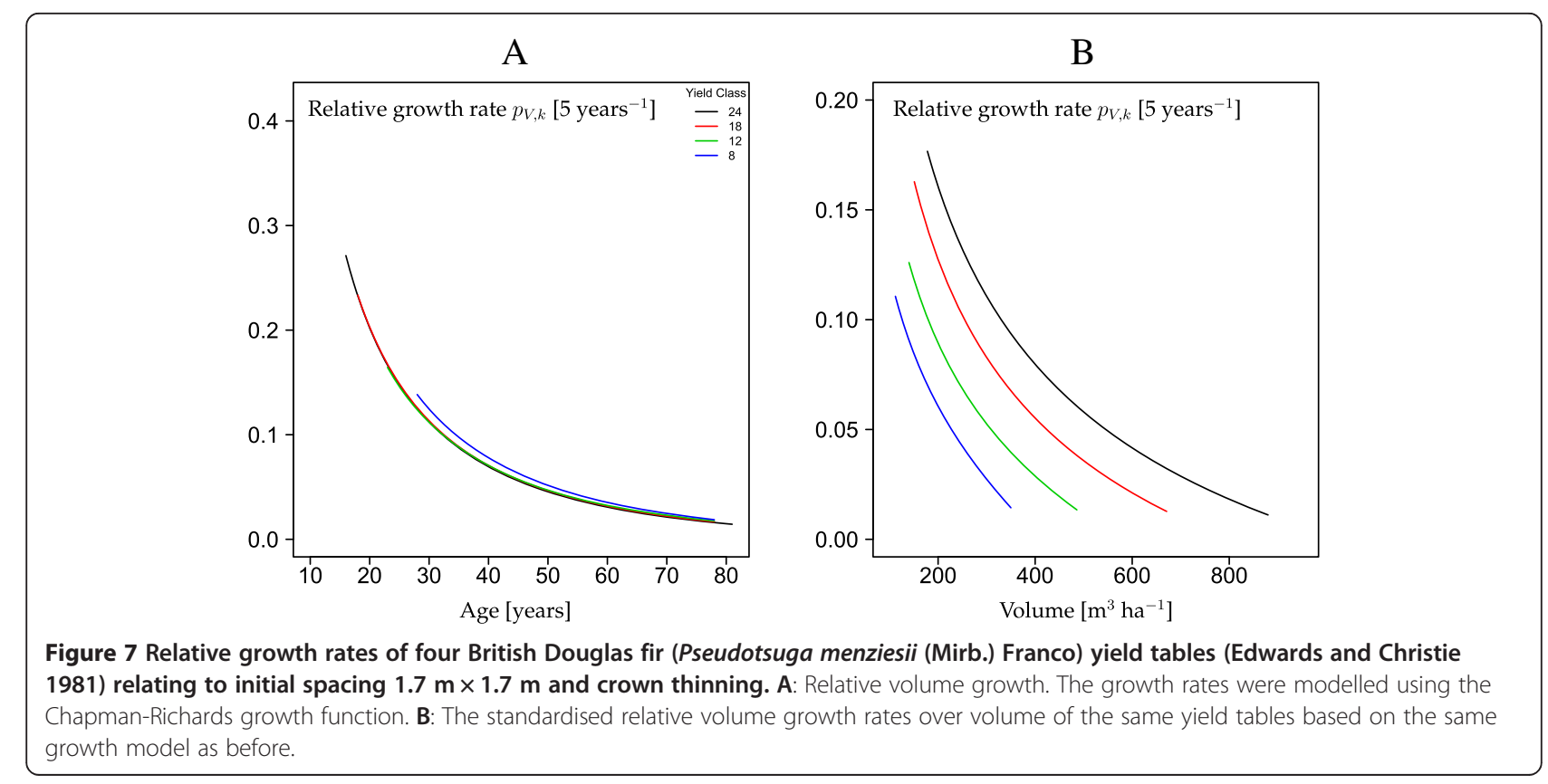


as the applicability is universal to any phenomenon involving growth processes.

\section{Competing interests}

The authors declare that they have no competing interests.

\section{Authors' contributions}

AP devised the concept of the article, carried out the data analysis/ modelling and wrote the majority of the text. AM was responsible for the mathematical correctness of the equations and also ensured consistent notations. Both authors read and approved the final manuscript.

\section{Acknowledgements}

Stephen T. Murphy, Jens Haufe, Owen Davies and Gareth Johnson of the Tyfiant Coed project have carefully analysed and kindly provided the timeseries and stem-analysis data used as examples in this review. We are also indebted to the late Günter Wenk who inspired the first author with his enthusiasm of quantifying and modelling relative growth processes.

Received: 1 December 2014 Accepted: 10 February 2015

Published online: 10 March 2015

\section{References}

Antanaitis V, Zagreev V (1969) Прирост леса. [Forest increment.]. Издательство лесная промышленность, Moscow

Blackman VH (1919) The compound interest law and plant growth. Ann Bot 33:353-360

Bolker BM (2008) Ecological Models and Data In R. Princeton University Press, Princeton

Cao QV (2014) Linking individual-tree and whole-stand models for forest growth and yield prediction. Forest Ecosyst 1:1-8

Causton DR (1977) A Biologist's Mathematics. Edward Arnold, London

Causton DR, Venus JC (1981) The Biometry of Plant Growth. Edward Arnold, London

Edwards PN, Christie JM (1981) Yield Models for Forest Management. Forestry Commission Booklet 48. Forestry Commission, Edinburgh

Evans GC (1972) The Quantitative Analysis of Plant Growth. Blackwell Scientific Publications, Oxford

Gayon J (2000) History of the concept of allometry. Am Zool 40:748-758

Gillner S, Rüger N, Roloff A, Berger U (2013) Low relative growth rates predict future mortality of common beech (Fagus sylvatica L.). For Ecol Manage 302:372-378

Gompertz B (1825) On the nature of the function expressive of the law of human mortality, and on a new mode of determining the value of life contingencies. Phil Trans Royal Soc 115:513-585

Hunt R (1982) Plant Growth Curves. The Functional Approach to Plant Growth Analysis. Cambridge University Press, Cambridge

Hunt R (1990) Basic Growth Analysis: Plant Growth Analysis for Beginners. Unwin Hyman, London

Jones O, Maillardet R, Robinson A (2009) Introduction to Scientific Programming And Simulation Using R. Chapman \& Hall/CRC, Boca Raton

Kangas Y (1968) Beschreibung des Wachstums der Bäume als Funktion ihres Alters. [Describing the growth of trees as a function of age.] Acta Forestalia Fennica, 90, Helsinki 1-136.

Matthews RW, Mackie ED (2006) Forest mensuration. A handbook for practioners. Forestry Commission, Edinburgh

Michaelis M, Menten ML (1913) Die Kinetik der Invertinwirkung. The kinetics of invertase action.]. Biochem Z 49:333-369

Murphy ST, Pommerening A (2010) Modelling the growth of Sitka spruce (Picea sitchensis (Bong.) Carr.) in Wales using Wenk's model approach. Allgemeine Forst- und Jagdzeitung 181:35-43

Nicke A (1988) Aufbau eines Bestandesentwicklungsmodells. [Construction of a stand development model.]. Beiträge für die Forstwirtschaft 22:71-74

Pienaar LV, Turnbull KJ (1973) The Chapman-Richards generalization of von Bertalanffy's growth model for basal area growth and yield in even-aged stands. Forest Sci 19:2-22

Rees M, Osborne CP, Woodward Fl, Hulme SP, Turnbull LA, Taylor SH (2010) Partitioning the components of relative growth rate: How important is plant size variation. Am Nat 176:E152-E161

Richards FJ (1959) A flexible growth function for empirical use. J Exp Bot 10:290-300
Rose KE, Atkinson RL, Turnbull LA, Rees M (2009) The costs and benefits of fast living. Ecol Lett 12:1379-1384

Turnbull LA, Paul-Victor C, Schmid B, Purves DW (2008) Growth rates, seed size, and physiology: Do small-seeded species really grow faster? Ecology 89:1352-1363

Verhulst P-F (1838) Notice sur la loi que la population pursuit dans son accroissement. [A note on population growth.]. Correspondence Mathematiques et Physiques 10:113-121

Weber R (1891) Lehrbuch der Forsteinrichtung. [Textbook of forest planning.]. Springer-Verlag, Berlin

Wenk G (1972) Zuwachsprognosen, Vorratsfortschreibung und Aufstellung bestandesindividueller Ertragstafeln mit Hilfe von Wachstumsmultiplikatoren. [Increment prognoses, projection of stand volume and stand-specific yield tables on the basis of growth multipliers.]. Wissenschaftliche Zeitschrift der Technischen Universität Dresden 21:1247-1249

Wenk G (1978) Mathematische Formulierung von Wachstumsprozessen in der Forstwirtschaft. [Mathematical formulation of growth processes in forestry]. Beiträge für die Forstwirtschaft 1:25-30

Wenk G (1994) A yield prediction model for pure and mixed stands. For Ecol Manage 69:259-268

Wenk G, Nicke A (1985) Zur Prognose der Bestandesentwicklung. [Projecting stand development.]. Beiträge für die Forstwirtschaft 19:173-176

Wenk G, Antanaitis V, Smelko S (1990) Waldertragslehre. [Forest growth and yield science.]. Deutscher Landwirtschaftsverlag, Berlin

Whitehead FH, Myerscough PJ (1962) Growth analysis of plants. The ratio of mean relative growth rate to mean relative rate of leaf area increase. New Phytologist 61:314-321

Zeide B (1989) Accuracy of equations describing diameter growth. Can J Forest Res 19:1283-1286

Zeide B (1993) Analysis of growth equations. Forest Sci 39:594-616

Zhang L, Moore JA, Newberry JD (1993) Disaggregating stand volume growth to individual trees. Forest Sci 39:295-308

\section{Submit your manuscript to a SpringerOpen ${ }^{\odot}$ journal and benefit from:}

- Convenient online submission

Rigorous peer review

- Immediate publication on acceptance

- Open access: articles freely available online

- High visibility within the field

- Retaining the copyright to your article

Submit your next manuscript at $\boldsymbol{\wedge}$ springeropen.com 